\title{
Isolation and Characterization of Lactic Acid Bacteria from Fermented Goat Milk in Tajikistan
}

\author{
Gyu-Sung Cho ${ }^{1,5}$, Claudia Cappello ${ }^{2}$, Katrin Schrader ${ }^{3}$, Olakunle Fagbemigun ${ }^{4}$, Folarin A. Oguntoyinbo ${ }^{4,7}$, \\ Claudia Csovcsics ${ }^{5}$, Niels Rösch ${ }^{1}$, Jan Kabisch ${ }^{1}$, Horst Neve ${ }^{1}$, Wilhelm Bockelmann ${ }^{1}$, Karlis Briviba ${ }^{5}$, Monica \\ Modesto $^{2}$, Elisabetta Cilli ${ }^{6}$, Paola Mattarelli ${ }^{2}$, and Charles M.A.P Franz ${ }^{1 *}$ \\ Max Rubner-Institut, Federal Research Institute for Nutrition and Food, Departments of ${ }^{1}$ Microbiology and Biotechnology, Hermann- \\ Weigmann-Str. 1, D-24103 Kiel, Germany \\ ${ }^{2}$ Department of Agricultural Food Sciences, University of Bologna, Viale Fanin 42, I-40127 Bologna, Italy \\ ${ }^{3}$ Department of Safety and Quality of Milk and Fish Products, Hermann-Weigmann-Str. 1, D-24103 Kiel, Germany \\ ${ }^{4}$ Department of Microbiology, Faculty of Science, University of Lagos, Akoka, Lagos, Nigeria \\ ${ }^{5}$ Physiology and Biochemistry of Nutrition, Haid-und-Neu-Str. 9, D-76131 Karlsruhe, Germany \\ ${ }^{6}$ Department of Cultural Heritage, University of Bologna, Via degli Ariani 1, I-48121 Ravenna, Italy \\ ${ }^{7}$ A.R. Smith Department of Chemistry and Fermentation Sciences, Appalachian State University, Boone, NC 28608
}

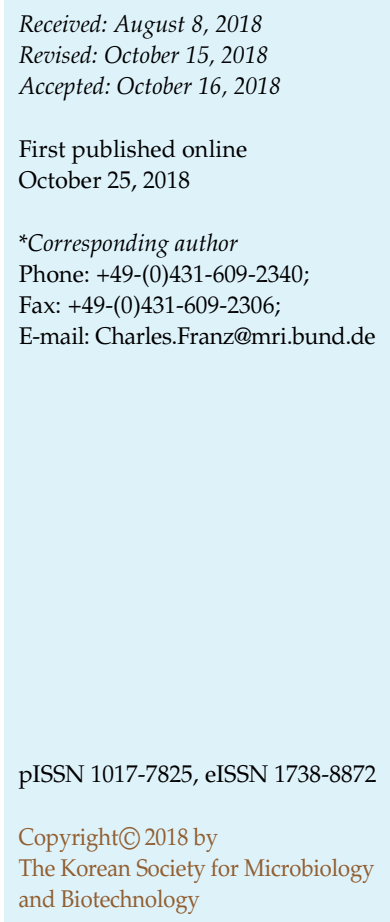

The lactobacilli associated with a fermented goat milk product from Tajikistan were isolated to characterize their technological properties and antibiotic resistances in order to assess their suitability for development as starter cultures. In this study, twenty three strains were identified by $16 \mathrm{~S}$ rRNA sequencing as typical dairy-associated lactic acid bacterial strains, i.e. L. plantarum, L. pentosus, L. delbrueckii, L. helveticus and L. paracasei. These strains were generally susceptible to most antibiotics tested in this study and this allowed a selection of strains as safe starters. The draft genomes of four representative strains were sequenced and the number of contigs of the four assembled genomes ranged from 51 to 245 and the genome sizes ranged from 1.75 to $3.24 \mathrm{Mbp}$. These representative strains showed differences in their growth behavior and $\mathrm{pH}$-reducing abilities in in vitro studies. The co-inoculation of these Lactobacillus spp. strains together with a yeast Kluyveromyces marxianus MBT-5698, or together with the yeast and an additional Streptococcus thermophilus MBT-2, led to a pH reduction to 3.4 after $48 \mathrm{~h}$. Only in the case of fermentation inoculated with the co-culture, the viscosity of the milk increased noticeably. In contrast, fermentations with single strains did not lead to gelation of the milk or to a decrease in the $\mathrm{pH}$ after $24 \mathrm{~h}$. The results of this study provide a comprehensive understanding of the predominant lactobacilli related to Tajikistani fermented milk products.

Keywords: Lactic acid bacteria, fermentation, Lactobacillus, whole genome sequencing, milk

\section{Introduction}

Traditional fermentations are in many rural areas of the world still the main method for food processing and preservation. These fermentations are often done empirically, based on cultural knowledge, and they often involve using back-slopping to inoculate a new fermentation with a small portion of a previous successful batch [1]. In traditional fermentations, the biochemical changes of the product during fermentation are brought about by wild bacteria or yeasts, which originate from the raw materials [2,3]. These are mainly lactic acid fermentations, in which lactic acid bacteria (LAB) such as Lactobacillus and Leuconostoc spp. predominate. However, in many traditional fermentations, 
the fermentation may also involve mixed cultures of yeasts, bacteria and fungi [4] and some microorganisms may participate in parallel, while others act in a sequential manner with a changing dominant microbiota during the course of the fermentation. Which of these microorganisms occur is often not known for many of such products. There is still a lack of scientific knowledge on the course of many of these fermentations, as the preparation of many traditional fermented foods today remains a house art [3, 5].

While fermentations of milk in Europe predominantly rely on the use of LAB starter cultures and these bacteria are predominantly associated with European milk products, in African and Asian countries milk fermentations appear to be mixed fermentations with $\mathrm{LAB}$ and often involving Lactococcus lactis, Streptococcus(S.) thermophilus and L. delbrueckii, but yeasts such as Saccharomyces cerevisiae and Candida spp. also may play a role in the fermentation [3, 6, 7]. As yeasts in traditional fermentations can occur in high numbers, they may have a technological role and possibly also an input on the typical organoleptic properties of the products.

Goat milk is often fermented in small pastoral communities in northern Tajikistan by traditional methods. These sour milk fermentations mostly rely on spontaneous fermentation and are made from raw, unpasteurized milk without defined starter cultures. An example is fermented goat milk from the Yaghnob Valley in Tajikistan, which is traditionally produced by back-slopping, and has been previously studied with respect to the yeasts occurring in the product [8]. So far however, the LAB, especially the lactobacilli associated with the product, has not been identified. In this study, we report on the identification of the lactobacilli associated with Tajikistan's traditionally fermented milk products, their technological properties like acidifying and milk coagulating abilities, as well as their antibiotic resistances, in order to assess their suitability for development as starter cultures.

\section{Materials and Methods}

\section{Bacterial Strains and Growth Conditions}

Twenty three presumptive Lactobacillus strains were obtained from a previous study that investigated yeasts from fermented goat's milk in Tajikistan [8]. In this study, we focused on the Lactobacillus strains with regard to their functional and safety characteristics and their suitability as starter culture for goat's milk fermentation. The strains were cultured aerobically in MRS (de Man, Rogosa and Sharpe) (Roth, Germany) broth at $37^{\circ} \mathrm{C}$ for $18 \mathrm{~h}$ and plated out on MRS agar at least twice before use in further experiments. The $S$. thermophilus MBT-2 and K. marxianus MBT-5698 cultures were fermented milk isolates from our own culture collection. S. thermophilus was cultured in M17 (Merck, Darmstadt, Germany) broth at $42^{\circ} \mathrm{C}$ and K. marxianus was cultured aerobically in malt extract (Merck) broth at $25^{\circ} \mathrm{C}$. Fresh overnight cultures were used to prepare stock solutions and these were kept at $-80^{\circ} \mathrm{C}$ in MRS broth containing $20 \%$ (v/v) glycerol (Merck, Germany).

\section{Phenotypic Characterization and Determination of Lactic Acid Configuration}

The Gram-reaction was determined by the $\mathrm{KOH}$ method using $3 \%(\mathrm{w} / \mathrm{v})$ aqueous $\mathrm{KOH}$ and visible amounts of bacterial colonies on glass slides according to Powers [9]. Growth at 10 and $45^{\circ} \mathrm{C}$ in MRS broth was evaluated after $24 \mathrm{~h}$ and $48 \mathrm{~h}$ of incubation, and the catalase reaction was tested with $3 \%(\mathrm{v} / \mathrm{v}) \mathrm{H}_{2} \mathrm{O}_{2}$ as described by Mathara et al. [10]. The type and amount of $\mathrm{D}(-)$ and $\mathrm{L}(+)$ isomers of lactic acid produced from glucose were determined by the UV method using a commercial test kit (r-biopharm, Germany), following the manufacturer's instruction. The carbohydrate fermentation profiles were assessed using the API50 $\mathrm{CH}$ (BioMerieux, Germany) identification system.

\section{$16 S$ rRNA Gene Sequencing and Strain Genotyping by RAPD- PCR}

The total genomic DNA of the 23 strains was isolated from $4 \mathrm{ml}$ of fresh overnight cultures grown at $37^{\circ} \mathrm{C}$ in MRS broth using the method of Pitcher et al. [11] as modified by Björkroth and Korkeala [12]. The $16 \mathrm{~S}$ rRNA gene was amplified using PCR. The PCR products were amplified in $50 \mu$ volumes containing $100 \mathrm{ng}$ template DNA, $1 \times$ Taq DNA polymerase buffer (GE Healthcare), $125 \mu \mathrm{M}$ of each dNTP (Peqlab, Erlangen, Germany), $25 \mathrm{pM}$ of each forward and reverse primer (16S fw 5'-AGA GTT TGA TCM TGG CTC AG-3' and 16S rev 5'-TAC GGY TAC CTT GTT ACG ACT-3') and $1.5 \mathrm{U}$ Taq DNA polymerase (GE Healthcare). The PCR reaction was done using an initial denaturation step at $94^{\circ} \mathrm{C}$ for $3 \mathrm{~min}$, followed by 32 cycles of $94^{\circ} \mathrm{C}$ for $30 \mathrm{sec}, 55^{\circ} \mathrm{C}$ primer annealing for $30 \mathrm{sec}, 72^{\circ} \mathrm{C}$ extension for $1 \mathrm{~min} 30 \mathrm{sec}$, followed by a final extension step at $72^{\circ} \mathrm{C}$ for $5 \mathrm{~min}$. All PCR products were purified using PCR cleaning columns (Qiagen, Hilden, Germany) and subsequently sequenced at GATC Biotech (Cologne, Germany). The sequences of $16 \mathrm{~S}$ rRNA gene PCR products were compared to those present in the EzTaxon database [13].

The randomly amplified polymorphic DNA (RAPD) PCR reaction was performed in a $50 \mu \mathrm{l}$ volume using $100 \mathrm{ng}$ chromosomal DNA, $1 \times$ Taq DNA polymerase buffer (GE Healthcare), $125 \mu \mathrm{M}$ of each dNTP's (Peqlab), 50 pM of primer M13 (5'-GAG GGT GGC GGT TCT-3') $3 \mathrm{mM} \mathrm{MgCl}_{2}$ and $1.5 \mathrm{U}$ Taq DNA polymerase (GE Healthcare) and methods as described before [14]. The PCR products were subjected to electrophoresis in $1 \times \mathrm{TBE}$ buffer for $16.5 \mathrm{~h}$ at $48 \mathrm{~V}$ on $1.8 \%(\mathrm{w} / \mathrm{v})$ agarose (Peqlab) gels. Gels were stained with ethidium bromide (Roth) and were visualized using a 
Fluorchem Imager 5500 system (Alpha Innotech, USA). The profile of RAPD band patterns was analyzed using the BioNumerics software packages (V 7.1 Applied Math, St-Martens-Latem, Belgium). The fingerprints were compared using the unweighted pair group method with arithmetic averages (UPGMA) clustering method.

\section{Whole Genome Sequence}

The total genomic DNA of selected lactobacilli was isolated using the peqGOLD Bacterial DNA Kit (Peqlab, Erlangen, Germany). For paired-end sequencing, the library of genomic DNA was prepared with an Illumina Nextera XT Library Prep Kit (Illumina, USA) and sequencing was done on the MiSeq sequencer with $2 \times$ 250 cycles. The raw paired-end sequencing data containing adapter sequences were trimmed using the Trimmomatic (v. 0.32) pipeline [15] and then de novo assembled with SPAdes (v. 3.11.1) [16]. The qualities of the obtained draft genome sequences were evaluated with the QUAST tool [17] and all contigs that were longer than $500 \mathrm{bp}$ were used for annotation by the RAST server [18]. In silico analyses to identify acquired antibiotic resistance genes were done using the Resfinder pipeline [19], while plasmid related sequences were detected using the Plasmidfinder pipeline [20].

\section{Fermentation of Goat's Milk with Lactobacillus Strains}

To determine the growth and acidification ability of potential starter strains, commercial, pasteurized goat's milk was obtained from a local supermarket in Germany and was used in fermentation experiments. The pasteurized goat's milk was inoculated with the Lactobacillus isolates identified in this study as L. plantarum TJA 26B, L. delbrueckii TJA 31, L. paracasei TJB 4 and L. helveticus TJA 10. The strains were inoculated singly at $1 \times 10^{7} \mathrm{CFU} / \mathrm{ml}$, or all four strains were inoculated together at this inoculation level. In addition, in one fermentation, the four selected strains were coinoculated with $S$. thermophilus MBT-2 $\left(1 \times 10^{7} \mathrm{CFU} / \mathrm{ml}\right)$ and Kluyveromyces marxianus MBT-5698 $\left(5 \times 10^{6} \mathrm{CFU} / \mathrm{ml}\right)$, while in another fermentation the 4 selected strains were co-inoculated with only the yeast $K$. marxianus $\left(5 \times 10^{6} \mathrm{CFU} / \mathrm{ml}\right)$. The yeast was chosen as $K$. marxianus was previously identified as a major component of the yeast population of this fermented product [8].

The milk was fermented in $50 \mathrm{ml}$ volumes at $30^{\circ} \mathrm{C}$ for $48 \mathrm{~h}$ and the $\mathrm{pH}$ and numbers of bacteria were determined after $0 \mathrm{~h}$ (immediately after inoculation), $24 \mathrm{~h}$ and $48 \mathrm{~h}$. For enumeration, $1 \mathrm{ml}$ of milk was removed and diluted in quarter-strength Ringer's solution in a ten-fold dilution series. Appropriate aliquots from appropriate dilutions were plated out onto MRS agar (Merck, Darmstadt, Germany) plates for determining the Lactobacillus counts and on M17 (Merck) agar for the S. thermophilus counts (only for the fermentation that contained S. thermophilus MBT-2. The yeast count was determined by plating onto YGC-agar (Merck) to which $0.2 \%$ of a $10 \%$ tartaric acid solution was added after autoclaving, to adjust the $\mathrm{pH}$ to 4.6 . Both MRS (anaerobic) and M17 plates (aerobic) were incubated at $30^{\circ} \mathrm{C}$ for 48 to $72 \mathrm{~h}$, while YGC agar plates were incubated at $25^{\circ} \mathrm{C}$ for $72 \mathrm{~h}$.

\section{Determination of Rheological Properties}

For the measurement of the viscosity, a rheometer MCR 302 (Anton Paar, Ostfildern, Germany) was used. Aliqouts of $0.7 \mathrm{ml}$ of the fermented product were placed into the cone and plate measuring system (diameter $50 \mathrm{~mm}$ ) using a syringe without needle. A flow curve was recorded at a temperature of $20^{\circ} \mathrm{C}$ using a logarithmic ramp of the shear rate $\left(10\right.$ to $\left.1,000 \mathrm{~s}^{-1}\right)$. These measurements were performed after $24 \mathrm{~h}$ and $48 \mathrm{~h}$ of fermentation.

\section{Antibiotic Resistance Profile}

The susceptibilities of the strains towards antibiotics were determined using the LAB susceptibility test medium (LSM) [21]. The minimum inhibitory concentrations (MICs) of ampicillin, gentamicin, tetracycline, erythromycin, streptomycin, vancomycin and chloramphenicol (Sigma, Germany) were determined. In order to do this, the overnight fresh cultures were inoculated at a concentration of $1 \times 10^{6} \mathrm{CFU} / \mathrm{ml}$ in $100 \mu \mathrm{l}$ of LSM using a 96-well plate (Merck, Darmstadt, Germany), which contained a two-fold dilution series of each of the antibiotics. The MIC breakpoint values for each antibiotic were adopted from EFSA [22].

\section{Results}

\section{Identification of the Lactic Acid Bacteria Strains and RAPD Strain Typing}

Twenty three predominant Lactobacillus strains were isolated from fermented milk from Tajikistan using MRS agar plates. All strains were gram positive, catalase-negative, produced lactate as an end product of metabolism and had rod-shaped morphology, and could therefore be characterized as presumptive lactobacilli. In order to identify the strains further to species and strain level, bacterial growth at different temperatures, the enantiomers of lactate produced, sequencing of the $16 \mathrm{~S}$ rRNA gene and RAPD PCR strain typing were done.

The lactobacilli could be identified as belonging to one of five species, i.e. L. paracasei, L. pentosus, L. delbrueckii, L. helveticus or L. plantarum (Table 1) by uploading the $16 \mathrm{~S}$ rRNA gene sequence into the EzTaxon database and searching for the nearest relatively. The relatedness scores for the EzTaxon analyses and the corresponding strain identifications are shown in Table 1 . The cluster analysis of RAPD-PCR fingerprints of lactobacilli from Tajikistani fermented milk obtained with primer M13 is shown in Fig. 1. Three major subgroups (I, II, and III) clustering at a correlation value of $r=43.3 \%$ could be discriminated. Most of the isolates clustered in subgroup I at $r=67.9 \%$ and all of these, except for one (TJB 4) which was identified as L. paracasei in $16 \mathrm{~S}$ rRNA gene sequencing, showed at least 2 common bands (Fig. 1). All isolates from subgroup I except 
Table 1. Differential characteristics of Lactobacillus isolates and 16S rRNA sequences.

\begin{tabular}{|c|c|c|c|c|c|c|}
\hline \multirow{2}{*}{ Strain } & \multirow{2}{*}{ Gas production } & \multicolumn{2}{|c|}{ Growth temperature } & \multirow{2}{*}{$\begin{array}{l}\text { Lactate } \\
\text { enantiomer }\end{array}$} & \multirow{2}{*}{ Related Taxa } & \multirow{2}{*}{$\begin{array}{c}\% \text { Similarity of } \\
16 \text { S Sequences [13] }\end{array}$} \\
\hline & & $15^{\circ} \mathrm{C}$ & $45^{\circ} \mathrm{C}$ & & & \\
\hline TJA 1 & - & - & - & $\mathrm{D}$ & L. delbrueckii subsp bulgaricus & $99.72 \%$ \\
\hline TJA 2 & - & - & + & $\mathrm{D}$ & L. delbrueckii subsp bulgaricus & $99.65 \%$ \\
\hline TJA 6A & - & + & + & DL & L. helveticus & $99.65 \%$ \\
\hline TJA 7A & - & + & + & DL & L. plantarum & $99.93 \%$ \\
\hline TJA 9 & - & - & + & $\mathrm{D}$ & L. plantarum & $99.93 \%$ \\
\hline TJA 10 & - & - & + & DL & L. helveticus & $100 \%$ \\
\hline TJA 11B & - & + & - & DL & L. helveticus & $100 \%$ \\
\hline TJA 11S & - & - & + & DL & L. helveticus & $99.79 \%$ \\
\hline TJA 12 & - & - & + & $\mathrm{D}$ & L. delbrueckii subsp bulgaricus & $99.71 \%$ \\
\hline TJA 16 & - & - & + & DL & L. helveticus & $100 \%$ \\
\hline TJA 17 & - & - & + & $\mathrm{D}$ & L. delbrueckii subsp bulgaricus & $99.58 \%$ \\
\hline TJA 19 & - & - & + & $\mathrm{D}$ & L. delbrueckii subsp bulgaricus & $99.72 \%$ \\
\hline TJA 20 & - & - & + & DL & L. helveticus & $99.93 \%$ \\
\hline TJA 21 & - & - & + & $\mathrm{D}$ & L. delbrueckiisubsp bulgaricus & $99.72 \%$ \\
\hline TJA $24 \mathrm{~A}$ & - & - & + & DL & L. helveticus & $100 \%$ \\
\hline TJA 26B & - & + & - & DL & L. plantarum & $99.79 \%$ \\
\hline TJA 26S & - & + & - & DL & L. pentosus & $99.81 \%$ \\
\hline TJA 27 & - & - & + & DL & L. helveticus & $100 \%$ \\
\hline TJA 28 & - & - & + & $\mathrm{D}$ & L. delbrueckii subsp bulgaricus & $99.79 \%$ \\
\hline TJA 29 & - & - & + & $\mathrm{D}$ & L. delbrueckii subsp lactics & $99.71 \%$ \\
\hline TJA 31 & - & - & + & $\mathrm{D}$ & L. delbrueckii subsp bulgaricus & $99.79 \%$ \\
\hline TJA 32 & - & - & + & DL & L. helveticus & $99.79 \%$ \\
\hline TJB 4 & - & + & - & $\mathrm{L}$ & L. paracasei & $99.93 \%$ \\
\hline
\end{tabular}

Production of $\mathrm{D}_{-}, \mathrm{L}_{-}$, and DL lactic acid as an end product.

+: Positive growth; -: negative growth

TJB 4 were identified by $16 \mathrm{~S}$ rRNA gene sequencing as L. delbrueckii isolates. These strains all produced the D- lactate enantiomer, which is typical for the L. delbrueckii species. Most L. delbrueckii strains are, in accordance with

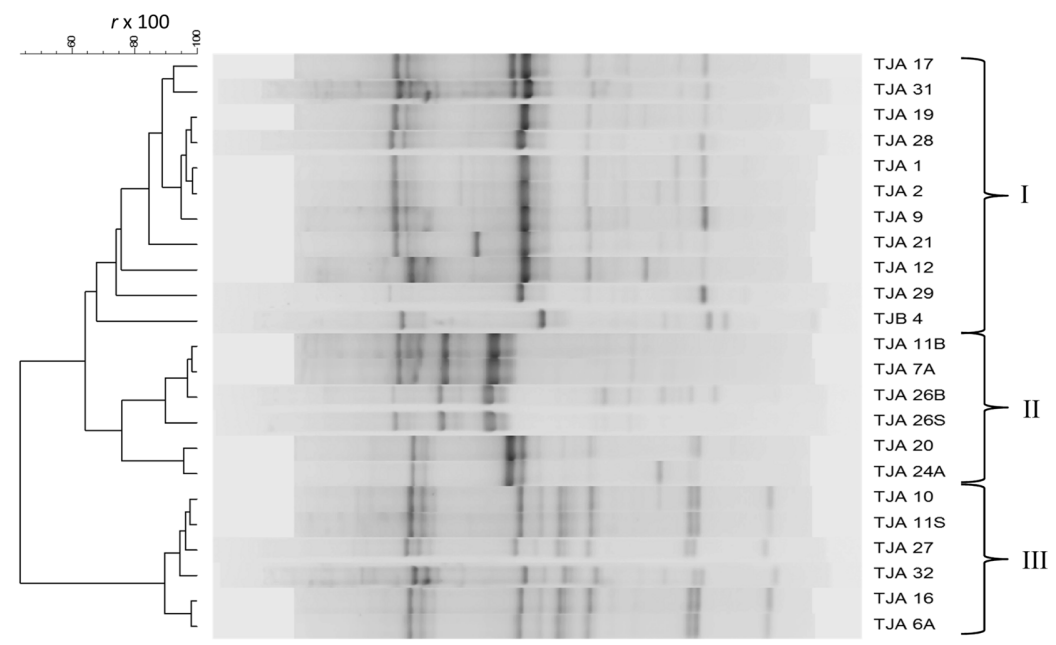

Fig. 1. Dendrogram obtained by UPGMA of correlation value $r$ of RAPD-PCR fingerprint patterns with primer M13 of strains isolated from fermented milk of Tajikistan. 
their usual habitat of milk, able to ferment lactose (Table 2) and accordingly all these strains in this study were able to utilize lactose.

RAPD fingerprinting furthermore showed that isolates in subgroup II clustered at $r=75.9 \%$ and 4 isolates (TJA 11B, 7A, 26B, and 26S) clustered very close at $r=89.8 \%$ (Fig. 1). A comparison in the EzTaxon database identified three of these isolates in subgroup II (TJA 11B, 7A, and 26B) as L. plantarum strains and one isolate (TJA 26S) as L. pentosus.

The six strains in subgroup III showed a very similar

Table 2. Carbohydrate fermentation of Lactobacillus strains.

\begin{tabular}{|c|c|c|c|c|}
\hline No. of strains & & & & \\
\hline $\begin{array}{l}\text { Carbohydrate } \\
\text { fermentation }\end{array}$ & $\begin{array}{c}(3) \\
\text { L. pentosus } \\
\text { (1) }\end{array}$ & $\begin{array}{c}\text { L. helveticus } \\
\text { (8) }\end{array}$ & $\begin{array}{l}\text { L. delbrueckii } \\
\qquad(10)\end{array}$ & $\begin{array}{c}\text { L. paracasei } \\
\text { (1) }\end{array}$ \\
\hline LARA & + & - & - & - \\
\hline RIB & - & - & - & - \\
\hline GAL & + & $+(75 \%)$ & - & + \\
\hline GLU & + & + & $+(80 \%)$ & + \\
\hline FRU & + & $+(37.5 \%)$ & + & + \\
\hline MNE & + & + & + & + \\
\hline RHA & + & - & - & - \\
\hline MAN & + & - & - & + \\
\hline MDM & + & - & - & - \\
\hline MDG & - & - & - & - \\
\hline NAG & + & $+(75 \%)$ & - & + \\
\hline AMY & + & - & - & - \\
\hline $\mathrm{ARB}$ & + & - & - & + \\
\hline SAL & + & $+(25 \%)$ & - & + \\
\hline CEL & + & - & - & + \\
\hline MAL & + & - & - & + \\
\hline LAC & + & + & + & + \\
\hline MEL & + & - & - & - \\
\hline SAC & + & - & - & + \\
\hline TRE & + & $+(50 \%)$ & - & + \\
\hline MLZ & + & - & - & + \\
\hline RAF & + & - & - & - \\
\hline GEN & + & - & - & + \\
\hline TUR & + & - & - & + \\
\hline DARL & + & - & - & - \\
\hline GNT & + & - & - & + \\
\hline
\end{tabular}

LARA L-arabinose, RIB D-Ribose, GAL D-galactose, GLU D-glucose, FRU Dfructose, MNE D-mannose, RHA L-rhamnose, MAN D-mannitol, MDM methyl- $\alpha$ D-mannopyranoside, MDG methyl- $\alpha$-D-glucopyranoside, NAG N-acetylglucosamine, AMY amygdalin, ARB arbutin, SAL salicin, CEL D-cellobiose, MAL D-Maltose, LAC D-lactose, MEL D-melibiose, SAC D-saccharose, TRE D-trehalose, MLZ Dmelezitose, RAF D-raffinose, GEN gentiobiose, TUR D-turanose, DARA Darabitol, GNT potassium gluconate

$+:$ Positive fermentation; percentage was calculated like positive number divided by total number of species, - : negative fermentation. band pattern, clustered together very closely at $r=89.7 \%$, and were identified as L. helveticus strains by $16 \mathrm{~S}$ rRNA gene sequencing. Interestingly, the two strains TJA 20 and TJA 24A clustering together with the L. plantarum strains in subgroup II were also identified as L. helveticus strains by $16 \mathrm{~S}$ rRNA gene sequencing. All strains identified by $16 \mathrm{~S}$ rRNA gene sequencing as L. helveticus, and which clustered together in subgroup III and subgroup II in RAPD fingerprinting, grew well at $45^{\circ} \mathrm{C}$, and they all fermented glucose, mannose, and lactose, which is typical for these bacteria.

\section{Whole Genome Data Analysis of Potential Starter Cultures}

The genome sequences of all major technologically important LAB are available, which has given new insight into functional genomics of LAB associated with food fermentations [23]. In our study, the genomes of four strains selected as representative of each species were sequenced and analyzed for typical functions related to fermentation activities and for the absence of transferable antibiotic resistance genes. Briefly, the contigs of the four assembled genomes ranged from 51 to 245 and the genome sizes ranged from 1.75 to $3.24 \mathrm{Mbp}$ (Table 3). The largest $\mathrm{N}_{50}$ value was 131,900 for L. plantarum TJA 26B and the lowest $\mathrm{N}_{50}$ value was 21,570 for L. helveticus TJA 10. No plasmid replication-related sequences were detected in the genome sequences of these strains. Two strains each possessed at least one bacteriocin gene, which may be important for inhibiting the growth of closely related bacterial strains. Thus, the presence of bacteriocin genes for helveticin $\mathrm{J}$ and plantaricins $\mathrm{EF}, \mathrm{JK}$ and $\mathrm{N}$ could be determined for L. helveticus TJA 10 and L. plantarum TJA 26B, respectively. Furthermore, the L. helveticus TJA 10, L. plantarum TJA 26B and the L. paracasei TJB 4 strains contained genes encoding a citrate lyase involved in citrate metabolism and an acetolactate synthase gene which is responsible for production of the diacetyl precursor $\alpha$-acetolactate (Table 3).

\section{Characterization of Goat's Milk Fermentation}

One strain of each species, i.e. L. plantarum strain TJA 26B, L. delbrueckii strain TJA 31, L. paracasei strain TJB 4 and L. helveticus strains TJA 10 were selected for further studies. When inoculated singly at approx. $1 \times 10^{7} \mathrm{CFU} / \mathrm{ml}$ in pasteurized goat milk, each of the strains grew well in the milk, but showed quite different acidification behavior. The L. plantarum TJA 26B showed only a ca. 1 log increase in growth to reach a final level of ca. $1 \times 10^{8} \mathrm{CFU} / \mathrm{ml}$ (Fig. 2). This growth led to only a moderate $\mathrm{pH}$ decrease 
Table 3. Genome data ${ }^{a}$ of selected Lactobacillus strains from Tajikistani fermented milk.

\begin{tabular}{lcccc}
\hline \multicolumn{1}{c}{ Strain } & TJA 10 & TJA 26B & TJA 31 & TJB 4 \\
\hline GenBank Accession No. & QNXC00000000 & QXEU00000000 & QNXB00000000 & QXET00000000 \\
No. of contigs & 254 & 122 & 54 & 244 \\
Largest contig & 61,465 & 341,241 & 424,489 & 180,575 \\
N50 & 21,570 & 131,900 & 107,123 & 51,965 \\
GC-content (mol\%) & 36.73 & 44.5 & 49.79 & 46.4 \\
Total length (bp ${ }^{1}$ ) & $1,889,241$ bp & $3,243,521$ bp & $1,742,687$ bp & $2,945,278$ bp \\
Plasmid sequence & n.d. ${ }^{2}$ & n.d. & n.d. & n.d. \\
CDS (coding sequence) & 2124 & 3233 & 1861 & 3186 \\
tRNA & 52 & 54 & 66 & 10 \\
rRNA & 6 & 4 & 3 & 11 \\
ncRNA & 3 & 4 & n.d. & 3 \\
Bacteriocin & Helveticin J & Plantaricin EF, N, and JK & n.d. & n.d. \\
Citrate lyase & $+^{3}$ & + & n.d. & + \\
Acetolactate synthase & + & n.d. & n.d. & n.d. \\
Acquired antibiotic resistance genes & n.d. & & & \\
\hline
\end{tabular}

${ }^{1}$; Base pair, ${ }^{2}$; not detected, ${ }^{3}$; gene detected.

from $\mathrm{pH} 6.6$ to ca. 5.4 (Fig. 3). The L. delbrueckii TJA 31 also grew from ca. $1 \times 10^{6} \mathrm{CFU} / \mathrm{ml}$ to ca. $1 \times 10^{8} \mathrm{CFU} / \mathrm{ml}$ and was able to reduce the $\mathrm{pH}$ down to $\mathrm{pH}$ 5.0. The L. paracasei strain TJB 4 and L. helveticus strains TJA 10 grew from $10^{6} \mathrm{CFU} / \mathrm{ml}$ to almost $1 \times 10^{9} \mathrm{CFU} / \mathrm{ml}$ and ca. $5 \times$ $10^{8} \mathrm{CFU} / \mathrm{ml}$, respectively (Fig. 2). These strains showed

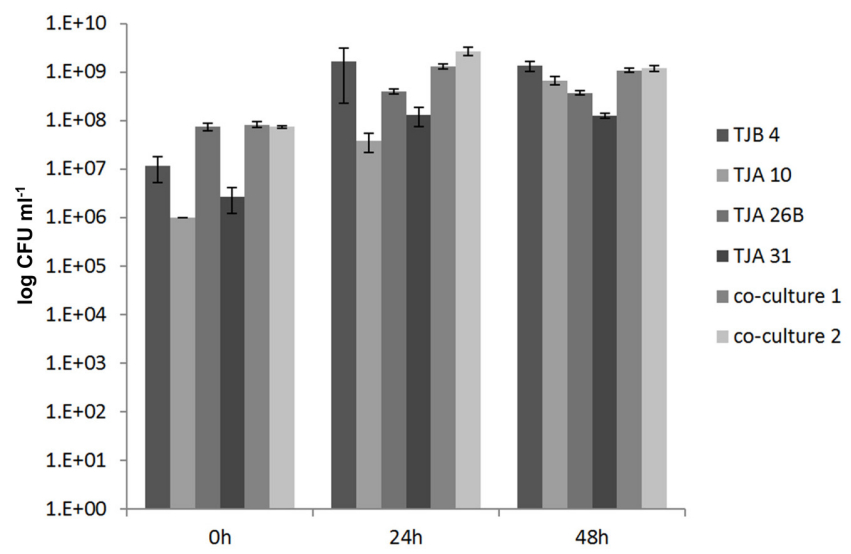

Fig. 2. Determination of total lactic acid bacteria counts in pasteurized goat's milk after inoculation starter cultures using MRS agar plates.

Co-culture 1: four starter lactic acid bacteria with the yeast Kluyveromyces marxianus MBT-5698, co-culture 2: four starter lactic acid bacteria with $S$. thermophilus MBT-2 and Kluyveromyces marxianus MBT-5698. Counts shown are from triplicate determinations with indicating a standard error. the highest $\mathrm{pH}$ lowering activity and reduced the $\mathrm{pH}$ from 6.5 to 4.5 or 3.8 , respectively (Fig. 3). When the goat's milk was inoculated with the four starter strains in combination with the yeast $K$. marxianus MBT-5698, the LAB counts on MRS agar increased from ca. $1 \times 10^{7} \mathrm{CFU} / \mathrm{ml}$ to ca. $1 \times$ $10^{9} \mathrm{CFU} / \mathrm{ml}$. The yeast counts on YGC medium increased from $5 \times 10^{5} \mathrm{CFU} / \mathrm{ml}$ to approx. $5 \times 10^{6}$ (data not shown). This co-inoculation of potential starter strains with yeast

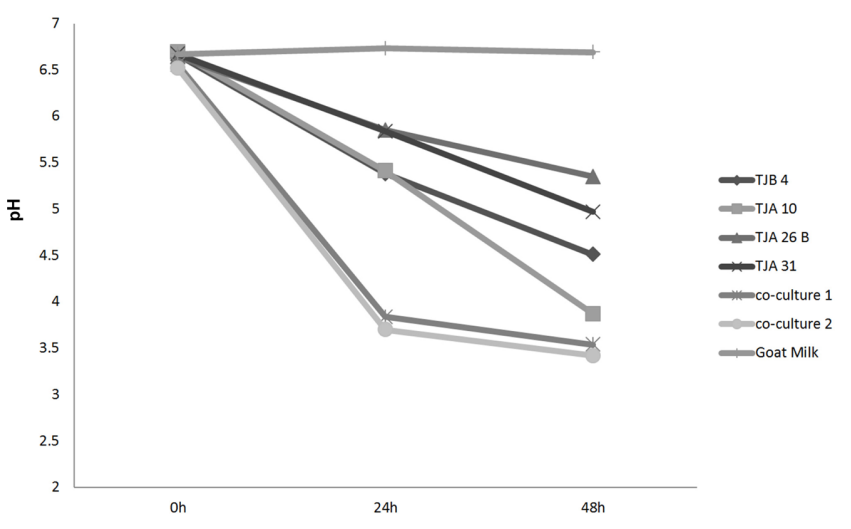

Fig. 3. $\mathrm{pH}$ development of goat's milk inoculated with starter lactic acid bacteria and co-culture with a $S$. thermophilus and yeast.

Co-culture 1: four starter LAB with the yeast Kluyveromyces marxianus MBT-5698, co-culture 2: four starter LAB with S. thermophilus MBT-2 and Kluyveromyces marxianus MBT-5698. Goat milk without inoculation of $\mathrm{LAB}$ as negative control. 

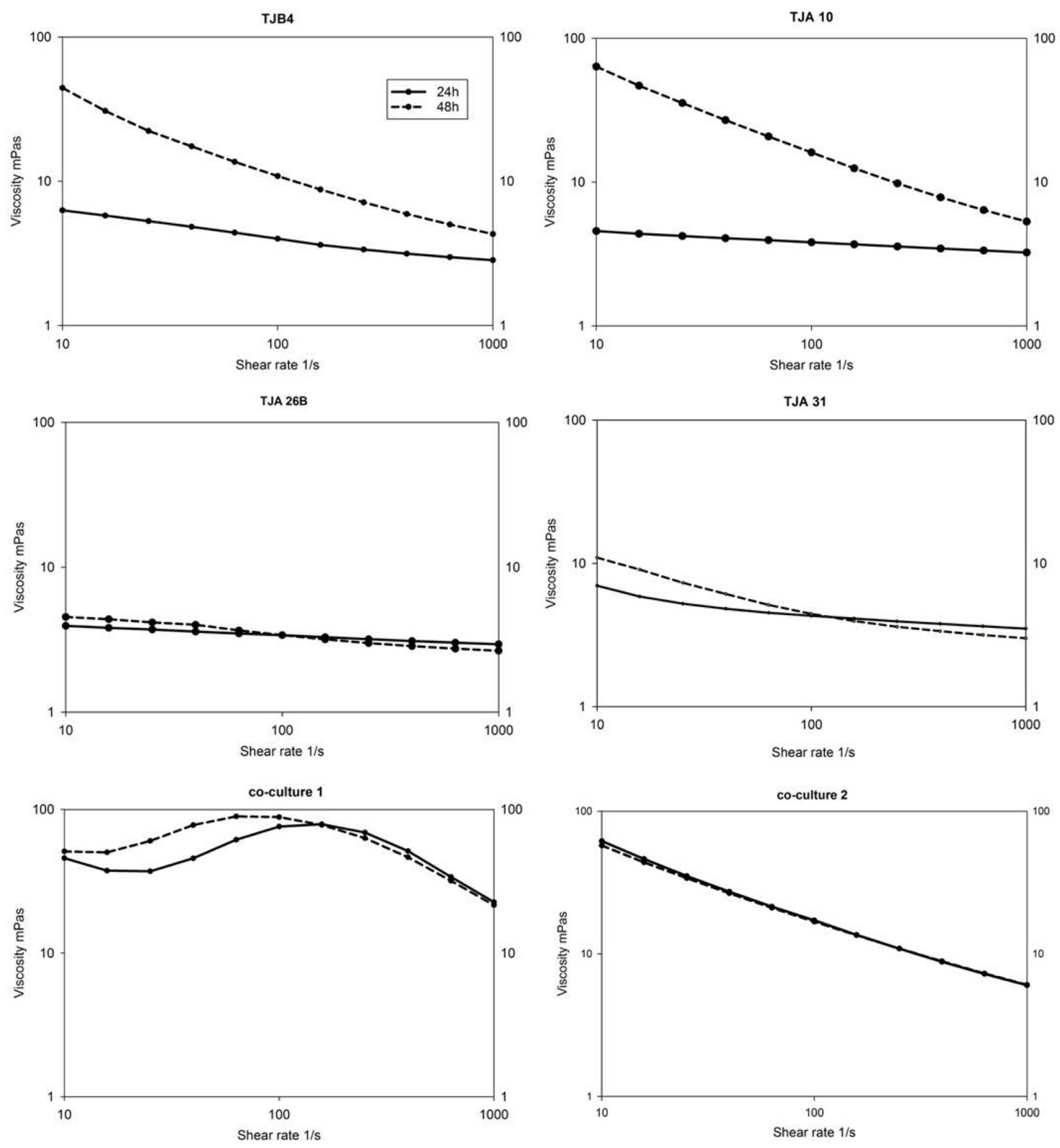

Fig. 4. Flow curves of the fermented milk products after $24 \mathrm{~h}$ (solid line) and after $48 \mathrm{~h}$ (dotted line) of fermentation.

led to the lowest determined $\mathrm{pH}$ of ca. $\mathrm{pH} 3.4$ (Fig. 3). Similarly, the co-inoculation of the four potential starters together with $S$. thermophilus MBT-2 and the yeast K. marxianus MBT-5698 also led to a LAB count on MRS of ca. $1 \times 10^{9} \mathrm{CFU} / \mathrm{ml}$ after $24 \mathrm{~h}$, while the yeast count increased from $5 \times 10^{4} \mathrm{CFU} / \mathrm{ml}$ to almost $1 \times 10^{6} \mathrm{CFU} / \mathrm{ml}$ (data not shown). In this case the $\mathrm{pH}$ of the fermentation decreased to $\mathrm{pH} 3.5$ (Fig. 3).

The flow curves of the different cultures are shown in Fig. 4. All samples, except co-cultures 1 and 2, showed similar flow behavior. After $24 \mathrm{~h}$ no significant increase in the viscosity was detected. This corresponded well with the results of the $\mathrm{pH}$ measurements (Fig. 3). The $\mathrm{pH}$ values of samples TJB 4, TJA 10, TJA 26B, and TJA 31 were higher than 5.5 (Fig. 3) and thus no gelation of the milk could occur, as indicated in Fig. 4. The co-cultures on the other hand, show $\mathrm{pH}$ values lower than 4.0, and that gelation was nearly completed. Co-culture 2 showed a typical flowthinning behavior. Viscosity decreased with higher shear rates, which were caused by aggregate destruction. Coculture 1 shows shear-thickening behavior in the range of 10 to 100 /s and shear-thinning behavior in the range above 
Table 4. Antibiotic resistance tests of isolates.

\begin{tabular}{|c|c|c|c|c|c|c|c|}
\hline \multirow{2}{*}{ Strain } & \multicolumn{7}{|c|}{ Minimum inhibitory concentration $(\mu \mathrm{g} / \mathrm{ml})$} \\
\hline & Amp & Ery & Tetra & Strep & Chlor & Gent & Van \\
\hline \multicolumn{8}{|l|}{ L. delbruecki } \\
\hline TJA 1 & 0.25 & 0.125 & 1 & 2 & 1 & 8 & 0.25 \\
\hline TJA 2 & Sensitive $^{b}$ & 0.25 & 16 & 16 & 2 & 2 & 0.5 \\
\hline TJA 9 & 0.5 & 0.125 & 16 & 16 & 4 & 8 & 0.5 \\
\hline TJA 12 & 16 & 0.5 & 8 & 8 & 4 & 4 & 0.5 \\
\hline TJA 17 & n.d. & n.d. & n.d. & n.d. & n.d. & n.d. & n.d. \\
\hline TJA 19 & n.d. & n.d. & n.d. & n.d. & n.d. & n.d. & n.d. \\
\hline TJA 21 & Sensitive & 0.5 & 16 & 8 & 2 & 2 & 0.5 \\
\hline TJA 28 & Sensitive & 0.25 & 16 & 32 & 1 & 2 & 1 \\
\hline TJA 29 & Sensitive & Sensitive & 16 & 32 & 1 & 16 & 0.5 \\
\hline TJA 31 & 0.25 & 0.5 & 8 & 8 & 2 & 4 & 0.5 \\
\hline TJA 32 & 1 & 0.25 & 1 & 4 & 4 & 2 & 0.25 \\
\hline \multicolumn{8}{|l|}{ L. helveticus } \\
\hline TJA 6A & Sensitive & 0.125 & $>256$ & 1 & 2 & 0.25 & $>256$ \\
\hline TJA 10 & 0.25 & 0.125 & 32 & 4 & 2 & 4 & 0.25 \\
\hline TJA 16 & Sensitive & 2 & 16 & 8 & 1 & 4 & 0.5 \\
\hline TJA 20 & Sensitive & Sensitive & 8 & 4 & 1 & 4 & 0.5 \\
\hline TJA $24 \mathrm{~A}$ & 0.25 & Sensitive & 8 & 2 & 1 & 4 & 0.5 \\
\hline TJA 27 & 0.25 & Sensitive & 16 & 8 & 2 & 8 & 0.5 \\
\hline \multicolumn{8}{|l|}{ L. plantarum } \\
\hline TJA 7A & Sensitive & 0.25 & $>256$ & 2 & 2 & 0.5 & $>256$ \\
\hline TJA 11S & 0.125 & 0.25 & 16 & 2 & 2 & 2 & 0.5 \\
\hline TJA 11B & Sensitive & 0.25 & $>256$ & 4 & 4 & 0.25 & $>256$ \\
\hline TJA 26B & 0.125 & 0.25 & 128 & 2 & 4 & 0.25 & $>256$ \\
\hline \multicolumn{8}{|l|}{ L. pentosus } \\
\hline TJA 26S & Sensitive & 0.125 & 8 & 4 & 2 & 0.5 & $>256$ \\
\hline \multicolumn{8}{|l|}{ L. paracasei } \\
\hline TJB 4 & 0.25 & 0.125 & 8 & 4 & 2 & 0.5 & $>256$ \\
\hline Breakpoints ${ }^{\mathrm{a}}$ for L. plantarum & 2 & 1 & 32 & n.r. & 8 & 16 & n.r. \\
\hline Breakpoints ${ }^{\mathrm{a}}$ for Lactobacillus obligate homofermentative & 1 & 1 & 4 & 16 & 4 & 16 & 2 \\
\hline
\end{tabular}

a Breakpoints according to EFSA [22], ${ }^{\text {b }}$ Growth inhibition occurs at $0.06 \mu \mathrm{g} / \mathrm{ml}$ As the least concentration, n.r: not required. n.d. : no bacterial growth on ISO medium Amp: ampicillin, Ery: erythromycin, Tetra: tetracycline, Strep: streptomycin, Chlor: chloramphenicol, Gent: gentamicin, Van: Vancomycin.

The value ' $>256$ ' means no growth inhibition occurred and this was the maximum concentration tested.

$100 / \mathrm{s}$ after 24 as well as after $48 \mathrm{~h}$.

\section{Antibiotic Resistance Profile}

In order to characterize the antibiotic resistances of the different lactobacilli, the LSM medium of Klare et al. [21], consisting of a mixture of $90 \%$ Iso-Sensitest and $10 \%$ MRS medium, was used to test the sensitivity towards 7 different antibiotics including ampicillin, erythromycin, tetracycline, streptomycin, chloramphenicol, gentamicin and vancomycin. In this study, most of lactobacilli strains were able to grow in the LSM medium, except for the TJA 17 and TJA 19 L. delbrueckii strains (Table 4). All L. plantarum strains isolated from Tajikistani fermented milk were sensitive to ampicillin, erythromycin, chloramphenicol and gentamicin, whereas all strains except L. plantarum TJA 11S were resistant to vancomycin. In this study, none of the strains, except the L. helveticus TJA 16 strain, were resistant to erythromycin and none of these strains were resistant to chloramphenicol. In the present study, however, almost all strains except L. delbrueckii strains TJA 28 and TJA 29 were 
susceptible to streptomycin and all strains were susceptible to gentamicin. The strains in this study therefore were generally susceptible to most antibiotics tested and this allowed a selection of strains as safe starter strains. Thus, the strains L. delbrueckii TJA 31, L. paracasei TJB 4 and L. helveticus TJA 10 tested for their application as starter culture in goat's milk did not display any potentially transferable resistances towards antibiotics such as tetracycline, erythromycin, ampicillin, chloramphenicol and streptomycin. Strain L. plantarum TJA 26B on the other hand, showed a relatively high MIC value of $128 \mu \mathrm{g} / \mathrm{ml}$ for tetracycline. However, the annotated sequence data showed that none of the four selected strains possessed any acquired antibiotic resistance genes (Table 3). Accordingly, no determinant for acquired tetracycline resistance could be determined to occur in the genome sequence of L. plantarum TJA 26B. In addition, no plasmid sequences could be determined in all four strains. Therefore, there appears to be no apparent danger of these strains with regard to transferable antibiotic resistances.

\section{Discussion}

L. delbrueckii subsp. bulgaricus is a microorganism that is known to be well adapted to the milk environment and together with $S$. thermophilus is a recognized starter bacterium for the production of yoghurt in Western countries. It was therefore not surprising to find the microorganism associated with the Tajikistani fermented milk products. According to Dellaglio et al. [24] and Adimpong et al. [25], the subspecies L. bulgaricus (L. delbrueckii subsp. bulgaricus) is the only subsp. which is unable to ferment sucrose. As all L. delbrueckii strains in this study could also not ferment sucrose (Table 2), it is likely that these strains belong to the L. delbrueckii subsp. bulgaricus. The only strain identified as L. paracasei by $16 \mathrm{~S}$ rRNA gene sequencing clustered apart from the L. delbrueckii strains in group I in the RAPDdendrogram. This strain produced only the L- lactic acid enantiomer and grew at 15 but not at $45^{\circ} \mathrm{C}$, which is typical for L. paracasei [26]. L. plantarum strains were commonly isolated and thus appeared to play role as predominant isolates in the fermentation of Tajikistani milk products. A previous study of Torriani et al. [27] showed that L. plantarum and L.pentosus are genotypically and phenotypically closely related. Thus L. plantarum and L. pentosus are difficult to distinguish on the basis of $16 \mathrm{~S}$ rRNA gene sequences. Based on the similar RAPD profiles of the four isolates, it is possible that isolate TJA 26S which was identified by $16 \mathrm{~S}$ rRNA sequencing as L. pentosus, may indeed also be a L. plantarum strain. These four strains which clustered together in subgroup II in the M13 RAPD fingerprint analysis (Fig. 1) were able to grow at $15^{\circ} \mathrm{C}$ but not $45^{\circ} \mathrm{C}$, produced DL-lactic acid and did not produce $\mathrm{CO}_{2}$ from glucose metabolism (Table 1). These characteristics are typical for L. plantarum and L. pentosus [28] strains and thus fitted well with the 16S rRNA gene sequence results. In our study, these four strains were also able to use melizitose as a carbohydrate source (Table 2), which indicates that these strains are indeed L. plantarum and L. pentosus, rather than L. paraplantarum, the latter which cannot ferment melizitose [28, 29]. These strains also produced both D- and L-lactic acid enantiomers, which were also characteristic for these bacteria [30].

Most of the L. helveticus strains isolated from Tajikistani fermented milk were able to utilize the carbohydrates galactose, fructose, trehalose and mannose, which have been described in a previous study [30]. L. helveticus is also a well-known strain for its role in the manufacture of some Swiss-type hard cheeses [31] and its presence in milk fermentations.

The RAPD strain typing method is a rapid, accurate and sensitive method for monitoring particular strains in a fermentation to which specific starter cultures were added [32]. However, the RAPD fingerprint technique only has limited potential identifying different Lactobacillus strains at the species level [27]. Thus, 16S rRNA gene sequence analysis was carried out to identify bacteria in this study. Nevertheless, our results showed that RAPD analysis in most cases grouped well the strains according to their $16 \mathrm{~S}$ rRNA gene sequence-determined identities. Accordingly, the L. delbrueckii and L. helveticus strains all clustered in separate groups, only group II contained both L. helveticus and the difficult to distinguish L. pentosus and L. plantarum strains.

Traditionally, L. helveticus and L. delbrueckii are considered as thermophilic lactobacilli used as starter cultures in the hard cheeses production, such as Swiss type cheeses or longripened Italian cheeses produced at elevated temperatures [31]. Accordingly, all these strains grew well at $45^{\circ} \mathrm{C}$ (Table 2). L. helveticus strains have also been reported to be proteolytic, producing certain peptides with healthpromoting properties during milk or dairy food fermentation [33]. Furthermore, probiotic features of L. helveticus, such as prevention of gastrointestinal infections, protective effects against pathogens, modulation of host immune response and adherence to epithelial cells were well described by Slattery et al. [34]. These lactobacilli, thus, were interesting for further study regarding their technological characteristics 
during the goat milk fermentation.

When single strains of each species, i.e. L. plantarum TJA 26B, L. delbrueckii TJA 31, L. paracasei TJB 4 and L. helveticus TJA 10 were inoculated singly in pasteurized goat milk, each of the strains grew well but showed quite different acidification behavior, from $\mathrm{pH} 3.8$ for L. helveticus TJA 10, to $\mathrm{pH} 5.4$ for L. plantarum TJA 26B. When the goat's milk was inoculated with all four strains including the yeast K. marxianus MBT-5698, this co-inoculation led to the lowest determined $\mathrm{pH}$ of ca. $\mathrm{pH}$ 3.4. Similarly, the coinoculation of the four potential starters together with S. thermophilus MBT-2 and the K. marxianus MBT-5698 also led to a low $\mathrm{pH}$ of the fermentation of 3.5. Clearly, therefore, as the aim for the use of starter cultures was to increase food safety, our results suggested that combinations of starters with yeasts and streptococci should be used to guarantee a deep enough acidification to below $\mathrm{pH} 4.0$, as this would prevent the growth of most foodborne pathogenic bacteria.

The lower $\mathrm{pH}$ brought about by the co-inoculation of the starter strains with the yeast may be explained for the symbiosis of S. thermophilus and L. delbrueckii in yoghurt fermentation (also known as proto-cooperation) [35]. Alternatively, the growth of the yeast may have improved conditions for growth of the cultures which did not grow well in the goat's milk, i.e. L. plantarum TJA 26B and L. helveticus TJA 10, which only grew to ca. $1 \times 10^{8} \mathrm{CFU} / \mathrm{ml}$ (Fig. 2). The yeast may have stimulated their growth by providing more anaerobic conditions when using the oxygen in the medium for its respiratory growth, or by providing growth-stimulating factors such as possibly vitamins, trace elements or amino acids. Indeed, a previous study of Plessas et al. [36] showed that synergistic effects could be determined during growth of L. helveticus, L. delbrueckii subsp. bulgaricus and K. marxianus. The authors suggested that this was also due especially to the presence of K. marxianus, which provides the LAB with growth factors such as vitamins, which in turn promote growth and lead to increased lactic acid production [36].

The flow curves of the different cultures in milk showed no significant increase in the viscosity, while they showed that gelation of the milk after fermentation with the cocultures was nearly completed. Co-culture 2 showed a typical flow-thinning behavior. Viscosity decreased with higher shear rates, which were caused by aggregate destruction. Co-culture 1 showed shear-thickening behavior in the range of 10 to $100 / \mathrm{s}$ and shear-thinning behavior in the range above $100 / \mathrm{s}$ after 24 as well as after $48 \mathrm{~h}$. This was probably caused by aggregates which blocked each other in the shear gap at lower shear rates and become destructed at higher shear rates. After 48 hours, cultures TJB 4, TJA 10, TJA 26B, and TJA 31 also showed shear-thinning behavior. The maximum viscosity directly corresponded to the lowest $\mathrm{pH}$ value.

There have been some previous reports on aminoglycoside resistances among Lactobacillus spp. such as L. casei and L. delbrueckii subsp. bulgaricus [37]. Whether antibiotic resistances are problematic depends on whether they can be transferable to other bacteria, i.e. whether they reside on mobile elements. In previous studies, several genes encoding antibiotic resistance determinants were identified from lactobacilli strains such as aph(3)-IIIa and ant(6) aminoglycoside resistance genes, as well as chloramphenicol (cat) [38], erythromycin-resistance (erm) [39] and tetracycline (tet) resistance genes [37, 40]. The tetracycline resistance gene tet(S), for example, was shown to be located on a plasmid in the probiotic L. plantarum strain CCUG 43738 [41]. Most antibiotic resistances of LAB strains seem to be intrinsic; however, in some cases, transferable resistances may occur, and according to the EFSA's Qualified Presumption of Safety (QPS) decision tree, these bacteria should be tested for transferable resistance genes before being considered as starter cultures for use in foods. A similar, intrinsic antibiotic resistance of L. plantarum towards vancomycin was previously reported [21,37, 42]. Ammor et al. [43] reported lactobacilli to be commonly resistant towards aminoglycosides such as gentamicin, kanamycin and streptomycin, and susceptible to other protein synthesis inhibitors. Generally, the isolates in this study showed little antibiotic resistances and this allowed the selection of susceptible strains for use as potential starter cultures.

In this study, therefore, the lactobacilli from Tajikistani fermented milk could be identified to consist of $L$. delbrueckii subsp. bulgaricus, L. helveticus, L. pentosus and L. paracasei strains. When these strains were co-inoculated together with the yeast $K$. marxianus, a synergistic growth stimulation and increased acid production associated with a lowered $\mathrm{pH}$ could be observed. The co-inoculation led to the lowering of $\mathrm{pH}$ levels below 5.5 which allowed gelling of milk. Most Lactobacillus isolates from Tajikistani fermented milk were generally susceptible to antibiotics. The whole genome sequence data showed that the four representative strains did not have any acquired antibiotic resistance genes; this would therefore not hinder the consideration of these strains as potential starter cultures. In addition, the whole genome sequence data showed that two strains possessed bacteriocin genes, which may be important for contributing to the safety of the products and to 
fermentation success. Furthermore, three strains possessed a gene which is important for diacetyl production, i.e. the citrate lyase gene. The metabolism of citrate to $\alpha$-acetolactate is part of the metabolic pathway for the production of diacetyl. Diacetyl formation occurs spontaneously from $\alpha$-acetolactate by decarboxylation, without specific enzymatic reaction [44]. The presence of this gene indicated that these three strains are potentially capable of producing the aroma compound diacetyl.

The low incidence of antibiotic resistance in the strains isolated from Yaghnob fermented milk could be related to the absence of use of antibiotics in this population: in fact, antibiotic therapy has not been used and traditional medicine with herbs has been mostly utilized to treat diseases. The microorganisms associated with the fermentation of Tajikistani milk have so far not been described. The results of this study clearly show that the microorganisms associated with fermentation are K. marxianus (as previously reported by [36]) and the Lactobacillus spp. identified in this study as consisting of L. delbrueckii subsp. bulgaricus, L. plantarum, L. helveticus and L. paracasei. The definition of these microorganisms as important for fermentation is a critical first step for the development of starter cultures and for paving the road to future industrial applications.

\section{Nucleotide Sequence Accession Number}

The whole-genome shotgun project of Tajikistani starter cultures can be accessed through BioProject number PRJNA479758 and has been deposited at DDB/ENA/ GenBank under the accession no. listed in Table 3.

\section{Acknowledgments}

The authors acknowledge the team of the Yaghnob Valley Mission directed by Prof. Antonio Panaino (Department of Cultural Heritage, University of Bologna, Italy) for their invaluable support in providing samples and fruitful discussion.

\section{Conflict of Interest}

The authors have no financial conflicts of interest to declare.

\section{References}

1. Holzapfel WH. 2002. Appropriate starter culture technologies for small-scale fermentation in developing countries. Int. J.
Food Microbiol. 75: 197-212.

2. Leroy F, De Vuyst L. 2004. Lactic acid bacteria as functional starter cultures for the food fermentation industry. Trends Food Sci. Technol. 15: 67-78.

3. Oguntoyinbo FA, Cho GS, Trierweiler B, Kabisch J, Rosch N, Neve H, et al. 2016. Fermentation of African kale (Brassica carinata) using L. plantarum BFE 5092 and L. fermentum BFE 6620 starter strains. Int. J. Food Microbiol. 238: 103-112.

4. Tamang JP, Watanabe K, Holzapfel WH. 2016. Review: diversity of microorganisms in global fermented foods and beverages. Front Microbiol. 7: 377.

5. Blandino A, Al-Aseeri ME, Pandiella SS, Cantero D, Webb C. 2003. Cereal-based fermented foods and beverages. Food Res. Int. 36: 527-543.

6. Franz CMAP, Huch M, Mathara JM, Abriouel H, Benomar N, Reid G, et al. 2014. African fermented foods and probiotics. Int. J. Food Microbiol. 190: 84-96.

7. Marsh AJ, O'Sullivan O, Hill C, Ross RP, Cotter PD. 2014. Sequence-based analysis of the bacterial and fungal compositions of multiple kombucha (tea fungus) samples. Food Microbiol. 38: 171-178.

8. Qvirist LA, De Filippo C, Strati F, Stefanini I, Sordo M, Andlid T, et al. 2016. Isolation, identification and characterization of yeasts from fermented goat milk of the Yaghnob Valley in Tajikistan. Front Microbiol. 7: 1690.

9. Powers EM. 1995. Efficacy of the Ryu nonstaining $\mathrm{KOH}$ technique for rapidly determining gram reactions of foodborne and waterborne bacteria and yeasts. Appl. Environ. Microbiol. 61: 3756-3758.

10. Mathara JM, Schillinger U, Kutima PM, Mbugua SK, Holzapfel WH. 2004. Isolation, identification and characterisation of the dominant microorganisms of kule naoto: the Maasai traditional fermented milk in Kenya. Int. J. Food Microbiol. 94: 269-278.

11. Pitcher DG, Saunders NA, Owen RJ. 1989. Rapid extraction of bacterial genomic DNA with guanidium thiocyanate. Lett. Appl. Microbiol. 8: 151-156.

12. Bjorkroth J, Korkeala H. 1996. rRNA gene restriction patterns as a characterization tool for Lactobacillus sake strains producing ropy slime. Int. J. Food Microbiol. 30: 293-302.

13. Kim OS, Cho YJ, Lee K, Yoon SH, Kim M, Na H, et al. 2012. Introducing EzTaxon-e: a prokaryotic $16 \mathrm{~S}$ rRNA gene sequence database with phylotypes that represent uncultured species. Int. J. Syst. Evol. Microbiol. 62: 716-721.

14. Yousif NM, Huch M, Schuster T, Cho GS, Dirar HA, Holzapfel WH, et al. 2010. Diversity of lactic acid bacteria from Hussuwa, a traditional African fermented sorghum food. Food Microbiol. 27: 757-768.

15. Bolger AM, Lohse M, Usadel B. 2014. Trimmomatic: a flexible trimmer for Illumina sequence data. Bioinformatics 30: 2114-2120.

16. Bankevich A, Nurk S, Antipov D, Gurevich AA, Dvorkin M, Kulikov AS, et al. 2012. SPAdes: a new genome assembly 
algorithm and its applications to single-cell sequencing. $J$. Comput. Biol. 19: 455-477.

17. Gurevich A, Saveliev V, Vyahhi N, Tesler G. 2013. QUAST: quality assessment tool for genome assemblies. Bioinformatics 29: 1072-1075.

18. Aziz RK, Bartels D, Best AA, DeJongh M, Disz T, Edwards RA, et al. 2008. The RAST Server: rapid annotations using subsystems technology. BMC Genom. 9: 75.

19. Zankari E, Hasman H, Cosentino S, Vestergaard M, Rasmussen S, Lund $\mathrm{O}$, et al. 2012. Identification of acquired antimicrobial resistance genes. J. Antimicrob. Chemother. 67: 2640-2644

20. Carattoli A, Zankari E, Garcia-Fernandez A, Voldby Larsen M, Lund O, Villa L, et al. 2014. In silico detection and typing of plasmids using PlasmidFinder and plasmid multilocus sequence typing. Antimicrob. Agents Chemother. 58: 3895-3903.

21. Klare I, Konstabel C, Muller-Bertling S, Reissbrodt R, Huys G, Vancanneyt $\mathrm{M}$, et al. 2005. Evaluation of new broth media for microdilution antibiotic susceptibility testing of Lactobacilli, Pediococci, Lactococci, and Bifidobacteria. Appl. Environ. Microbiol. 71: 8982-8986.

22. EFSA. 2012. Guidance on the assessment of bacterial susceptibility to antimicrobials of human and veterinary importance. EFSA J. 10: 1-10.

23. Douillard FP, de Vos WM. 2014. Functional genomics of lactic acid bacteria: from food to health. Microb. Cell Fact. 13(Suppl 1): S8.

24. Dellaglio F, Felis GE, Castioni A, Torriani S, Germond JE. 2005. Lactobacillus delbrueckii subsp. indicus subsp. nov., isolated from Indian dairy products. Int. J. Syst. Evol. Microbiol. 55: 401-404.

25. Adimpong DB, Nielsen DS, Sorensen KI, Vogensen FK, Sawadogo-Lingani H, Derkx PM, et al. 2013. Lactobacillus delbrueckii subsp. jakobsenii subsp. nov., isolated from dolo wort, an alcoholic fermented beverage in Burkina Faso. Int. J. Syst. Evol. Microbiol. 63: 3720-3726.

26. Pot B, Felis GE, Bruyne KD, Tsakalidou E, Papadimitriou K, Leisner J, et al. 2014. The genus Lactobacillus, pp. 249-353. Lactic Acid Bacteria, Ed. John Wiley \& Sons, Ltd,

27. Torriani S, Felis GE, Dellaglio F. 2001. Differentiation of Lactobacillus plantarum, L. pentosus, and L. paraplantarum by recA gene sequence analysis and multiplex PCR assay with recA gene-derived primers. Appl. Environ. Microbiol. 67: 3450-3454.

28. Kostinek M, Specht I, Edward VA, Schillinger U, Hertel C, Holzapfel WH, et al. 2005. Diversity and technological properties of predominant lactic acid bacteria from fermented cassava used for the preparation of Gari, a traditional African food. Syst. Appl. Microbiol. 28: 527-540.

29. Bringel F, Curk MC, Hubert JC. 1996. Characterization of lactobacilli by Southern-type hybridization with a Lactobacillus plantarum pyrDFE probe. Int. J. Syst. Bacteriol. 46: 588-594.

30. Naser SM, Hagen KE, Vancanneyt M, Cleenwerck I, Swings J,
Tompkins TA. 2006. Lactobacillus suntoryeus Cachat and Priest 2005 is a later synonym of Lactobacillus helveticus (Orla-Jensen 1919) Bergey et al. 1925 (Approved Lists 1980). Int. J. Syst. Evol. Microbiol. 56: 355-360.

31. Giraffa G. 2014. Lactobacillus helveticus: importance in food and health. Front Microbiol. 5: 338.

32. Sesena S, Sanchez I, Palop L. 2004. Genetic diversity (RAPDPCR) of lactobacilli isolated from "Almagro" eggplant fermentations from two seasons. FEMS Microbiol. Lett. 238: 159-165.

33. Griffiths MW, Tellez AM. 2013. Lactobacillus helveticus: the proteolytic system. Front Microbiol. 4: 30.

34. Slattery L, O'Callaghan J, Fitzgerald GF, Beresford T, Ross RP. 2010. Invited review: Lactobacillus helveticus--a thermophilic dairy starter related to gut bacteria. J. Dairy Sci. 93: 44354454 .

35. Settachaimongkon S, Nout MJ, Antunes Fernandes EC, Hettinga KA, Vervoort JM, van Hooijdonk TC, et al. 2014. Influence of different proteolytic strains of Streptococcus thermophilus in co-culture with Lactobacillus delbrueckii subsp. bulgaricus on the metabolite profile of set-yoghurt. Int. J. Food Microbiol. 177: 29-36.

36. Plessas S, Bosnea L, Psarianos C, Koutinas AA, Marchant R, Banat IM. 2008. Lactic acid production by mixed cultures of Kluyveromyces marxianus, Lactobacillus delbrueckii ssp. bulgaricus and Lactobacillus helveticus. Bioresour. Technol. 99: 5951-5955.

37. Devirgiliis C, Zinno P, Perozzi G. 2013. Update on antibiotic resistance in foodborne Lactobacillus and Lactococcus species. Front Microbiol. 4: 301.

38. Lin CF, Fung ZF, Wu CL, Chung TC. 1996. Molecular characterization of a plasmid-borne (pTC82) chloramphenicol resistance determinant (cat-TC) from Lactobacillus reuteri G4. Plasmid 36: 116-124.

39. Cataloluk O, Gogebakan B. 2004. Presence of drug resistance in intestinal lactobacilli of dairy and human origin in Turkey. FEMS Microbiol. Lett. 236: 7-12.

40. Huys G, D'Haene K, Collard JM, Swings J. 2004. Prevalence and molecular characterization of tetracycline resistance in Enterococcus isolates from food. Appl. Environ. Microbiol. 70: 1555-1562.

41. Huys G, D'Haene K, Swings J. 2006. Genetic basis of tetracycline and minocycline resistance in potentially probiotic Lactobacillus plantarum strain CCUG 43738. Antimicrob. Agents Chemother. 50: 1550-1551.

42. Temmerman R, Pot B, Huys G, Swings J. 2003. Identification and antibiotic susceptibility of bacterial isolates from probiotic products. Int. J. Food Microbiol. 81: 1-10.

43. Ammor MS, Florez AB, Mayo B. 2007. Antibiotic resistance in non-enterococcal lactic acid bacteria and bifidobacteria. Food Microbiol. 24: 559-570.

44. Hugenholtz J. 1993. Citrate metabolism in lactic acid bacteria. FEMS Microbiol. Rev. 12: 165-178. 